- No formal handover of HEADSSS to ICTS team.

- No documentation of health promotion.

Conclusion HEADSSS had been introduced effectively by circulating completion rates but use has not been maintained reliably. Suggested improvements include focusing on younger patients and further handover prompts.

The process of HEADSSS assessment, social services referral and ICTS review is discoordinated. Suggested improvements include educating clinicians, form adjustments, comprehensive information leaflets and linking local organisations such as SORTED (substance misuse) and the 'early-help-hub' (family support) to address psychosocial needs and prompt health promotion.

\section{G172(P) MATERNAL ATTITUDES TO SAFE INFANT SLEEPING PRACTICES}

${ }^{1} \mathrm{~N}$ O'Brien, ${ }^{2} \mathrm{C}$ McGarvey, ${ }^{2} \mathrm{~K}$ Hamilton, ${ }^{1} \mathrm{~B}$ Hayes. ${ }^{1}$ Neonatology, The Rotunda Maternity Hospital, Dublin, Ireland; ${ }^{2}$ National Paediatric Mortality Register, The Children's University Hospital, Temple St, Dublin, Ireland

\subsection{6/archdischild-2020-rcpch.143}

Aims Educational campaigns have resulted in a $50-75 \%$ reduction in Sudden Infant Death Syndrome (SIDS) worldwide since the 1990's. Current Irish and UK SIDS rates are 0.3/1000 live births. Despite these successes, SIDS accounts for up $40 \%$ to post-neonatal infant mortality.

Risks include prone or side sleeping, co-sleeping, excess bedding, prematurity, low birth weight and smoke exposure. Protective factors include breastfeeding, room-sharing and immunisations. Sleeping bags and cardio-respiratory monitors are not protective. Sleeping nests are harmful.

\begin{tabular}{ll} 
Abstract G172(P) Table 1 & \\
\hline Maternal Demographics & $\mathrm{n}=450$ \\
\hline Age & \\
$<25$ years & $9.4 \%$ \\
$>40$ years & $8.9 \%$ \\
Parity & \\
Primigravida & $45.3 \%$ \\
$\geq$ Gravida 3 & $61.4 \%$ \\
Marital Status & \\
Married & $62.4 \%$ \\
Co-habiting & $15.3 \%$ \\
Single & $21.5 \%$ \\
Education & \\
Further education & $76 \%$ \\
Higher secondary school & $15.3 \%$ \\
Lower secondary school & $5.2 \%$ \\
Primary school & $1.6 \%$ \\
Feeding & \\
Exclusive breastfeeding & \\
Combined feeding & $62 \%$ \\
Formula feeding & $10.2 \%$ \\
Bedding & $27.8 \%$ \\
Cleeping bags & \\
Pillows & $26.8 \%$ \\
Sleeping pods & $11.7 \%$ \\
\hline & $9.5 \%$ \\
\hline
\end{tabular}

In $2000,60 \%$ of mothers smoked, $13 \%$ co-slept, and 54\% of infants slept supine. We wished to reassess maternal knowledge and associated variables regarding safe infant sleeping practices.

Methods A cross-sectional survey was completed with mothers prior to discharge in a tertiary maternity hospital that has 8,000 deliveries annually. Exclusion criteria included previous miscarriage or SIDS, and infants admitted to the neonatal unit.

Results 450 mothers were recruited. Demographics are given below. $8.9 \%$ smoked antenatally, with $20 \%$ of infants exposed to household smoke. $84.6 \%$ of infants slept supine, with $15.4 \%$ sleeping either side or prone. $67.4 \%$ used a monitor. $31.7 \%$ used a soother. $44.4 \%$ had health insurance, and $20.2 \%$ had a medical card.

Mothers $<25$ years were more likely to smoke $(31 \%$ Vs $6 \%, \mathrm{p}<0.001)$, and less likely to breastfeed $(50 \%$ Vs $75 \%$, $\mathrm{p}<0.01$ ). Age had no interaction with sleeping position. Further analysis on the effect of maternal age, education, health insurance and ethnicity is pending.

Conclusion Globally there has been a reduction in SIDS and an improvement in infant sleeping practices. However, deprived families are over-represented in SIDS deaths, and campaigns need to specifically target this cohort. Furthermore, parents need to be educated on evidence-based practices, as many devices marketed to reduced SIDS have no proven benefit, and others are harmful.

\section{G173(P) HEALTH BENEFITS OF EXPOSURE TO WOODLAND AND THE BENEFITS OF FOREST SCHOOLS FOR CHILDREN AND THOSE WITH ADDITIONAL NEEDS}

F Finlay, S Lenton. Community Child Health, Virgin Care, Bath, UK

\subsection{6/archdischild-2020-rcpch.144}

Aims There is an increasing interest in prevention and population health following the publication of the NHS Long-Term Plan and Advancing Our Health, Prevention in the 2020's. This paper examines the existing evidence on the health benefits of exposure to woodland and the benefits of forest schools for children and those with additional needs.

Method Literature review.

Results The adult literature supports the theory that exposure to natural environments are health promoting with evidence that forest bathing (Shinrin-yoku) can:

- Reduce blood pressure and heart rate

- Reduce urinary adrenaline and serum cortisol

- Improve mental well-being by reducing anxiety, depression, fatigue

- Positively affect the immune system by increasing natural killer cells and intracellular anticancer proteins

- Reduce recovery time after surgical intervention.

The physiological benefits have been attributed to psychological benefits acting through the hypothalamic-pituitary axis and the impact ofphytoncides (naturally occurring aromatic volatile substances emitted by trees) having antioxidant and anti-inflammatory effects. As yet there are few studies on health benefits for children and young people.

In contrast, there are many observational studies describing the benefits of Forest schools on education outcomes. The Forest School philosophy originated in Scandinavia during the 
1950 s and has been widely adopted in education systems. Although titled 'Forest schools' it is the philosophy which is more important than the forest environment per se. It is based on regular exposure to a natural environment which offers children the opportunity to take appropriate risks and gain resilience, confidence and independence as creative learners. Improved outcomes include:

- Increased self-esteem and self-confidence

- Improved social skills

- The development of language and communication skills

- Improved physical motor skills

- Improved motivation and concentration

- Increased knowledge and understanding of the environment

Conclusions The benefits of the natural environment is little surprise considering the human race coexisted with nature for 99.99\% of its evolution. The Biophilia Hypothesis recognises the biological attraction of nature to human beings and promotes the benefits of intimate contact with nature. Preliminary results suggest that contact with nature should be encouraged in health and education environments.

\section{G174(P) ELECTRIC SCOOTERS, THEIR SAFETY AND THE LAW AROUND THEIR USE IN THE UK}

${ }^{1} \mathrm{G}$ Guiton, ${ }^{2} \mathrm{~F}$ Finlay. ${ }^{1} \mathrm{~F} 1$ Doctor, Dorset County Hospital, Dorchester, UK; ${ }^{2}$ Community Child Health, Virgin Care, St Martins Hospital, Bath, UK

\subsection{6/archdischild-2020-rcpch. 145}

Aims To review the popularity of electric (E) scooters, their safety and the law around their use in the UK.

Methods A review of the literature.

Results E-scooters are rising in popularity in both children and adults and have the potential to provide an attractive solution to common urban mobility problems - they are fun to use, cheap to run, improve mobility around cities, reduce congestion levels and do not use traditional fuels which have severe environmental implications. They are fitted with rechargeable batteries and have speeds ranging from $9 \mathrm{mph}$ to $15 \mathrm{mph}$.

Sharing schemes are popular and available in over 100 cities in Europe and US, users collecting them from various points around a city, renting them using an app and docking them when no longer required. In 2018, 84 million trips were taken on shared micromobility in the US - more than double the number of trips in 2017.

However in the UK the picture is very different. E-scooters cannot be legally ridden on the road or in cycle lanes and the Highway Act 1835 (originally written for horses and carts!) also prohibits their use on a pavement. They may only be legally ridden on private land with the permission of the landowner. This is due to their classification as 'powered transporters' or 'personal light electric vehicles' by Department for Transport (DfT) making them subject to motor vehicle laws, including the need for insurance, license, tax, MOT, visible rear red lights and number plates.

The design of E-scooters makes them portable, light and efficient but also makes them unsafe. They have two small tyres their user being inches from the road surface, resulting in a significant risk of traumatic injury, particularly when going over drain covers or potholes. Few wear helmets when riding them and there have been numerous injuries and deaths reported in various countries.
Conclusion With the shift to become more environmentally aware a 'future of mobility review' is considering how new types of vehicles, E-scooters, will change transport. It will also explore whether current laws should be changed to facilitate innovation while prioritising safety. Children need to be aware of the current laws with regard to their use and should be encouraged to wear helmets.

\section{Children's cancer and leukaemia group (CCLG) and paediatric special interest group: british society of haematology}

\section{Plenary}

\section{P05 WHAT ARE THE SIGNS AND SYMPTOMS OF BONE TUMOURS IN CHILDHOOD? ARE THE GREAT BRITISH PUBLIC AWARE OF THEM?}

${ }^{1} \mathrm{D}$ Shanmugavadivel, ${ }^{1} \mathrm{JF}$ Liu, ${ }^{2} \mathrm{~A}$ Stewart, ${ }^{2} \mathrm{~A}$ Gamble, ${ }^{1} \mathrm{D}$ Walker. ${ }^{1}$ Children's Brain Tumour Research Centre, University of Notitngham, Nottingham, UK; ${ }^{2}$ Children's Cancer and Leukaemia Group, CCLG, Leicester, UK

\subsection{6/archdischild-2020-rcpch.146}

Aims Bone tumours in children/young people are often associated with significant diagnostic delay, increasing the risk of amputation. The total diagnostic interval is a sum total of the patient and system interval. The HeadSmart campaign showed a national awareness campaign based on high quality evidenced based guidance halved time to diagnosis. We conducted a systematic review and meta-analysis to identify the core signs/symptoms and a public survey to understand public awareness of these symptoms.

Methods Medline, Pubmed and Embase databases were searched from January 2005 - August 2015. Key words included 'bone tumour(s)', 'bone neoplasm(s)', 'diagnosis', 'signs(s)', 'symptom(s)', 'presentation(s)'. All papers discussing bone tumour presentation were included. Pooled proportions (\%) of children with each sign/symptom at diagnosis were estimated. A face-to-face opinion survey ( $\mathrm{n}=1000 ; 475$ males) was conducted by Ipsos MORI. Questions included perception of cancer risk, confidence in recognising signs/symptoms and urgency of seeking medical advice.

Results The search strategy identified 15477 papers. 713 papers were reviewed in full; 11 met the inclusion criteria, describing the symptoms/signs at diagnosis in 1246 children. 29 symptoms/signs were recorded but only those that occurred in $2 \%$ or more of patients are reported. These were pain (76\%), swelling (21\%), fever (4\%), history of trauma (3\%), functional limitation (3\%), palpable mass $(3 \%)$, pain and swelling $(2 \%)$, volume increase $(2 \%)$, limp $(2 \%)$ and pathological fracture $(2 \%)$. Public awareness of the top 4 presenting symptoms of bone tumours were low. $23 \%$ of the public identified recurrent or persistent bone pain as a symptom of cancer; $27 \%$ identified swelling of bone or joint; $21 \%$ identified fever and $14 \%$ thought a slow recovery after injury or trauma could be a sign of cancer.

Conclusions This is the first systematic review on paediatric bone tumours to our knowledge. It provides strong evidence of the common presentations and will form the basis of a new RCPCH endorsed clinical guideline on the assessment/ investigation of suspected bone tumours. The results of the 